\section{Comparison of some physical and physiological characteristics of the male sedentaries, male handball players and male wrestlers whose ages were between 13 and 15}

\author{
Ömer Alıc1 ${ }^{1}$ \\ Rüçhan İri ${ }^{2}$
}

\begin{abstract}
The study aimed at the comparison of some physical and physiological characteristics of the male sedentaries, male handball players and male wrestlers whose ages were between 13 and 15 .

77 male individuals (sedentaries $=26$, handball players $=26$ and wrestler $=25$ ) participated voluntarily. Height, weight and BMI values of the subjects were measured and tests for right and left hand grip strengths, leg and back strength, $20 \mathrm{~m}$ sprint test, $30 \mathrm{sec}$ sit-up, push-up, sit-reach (flexibility), respiratory function (FVC, VC, $\mathrm{FEV}_{1}, \mathrm{PEF}$ ) and counter movement jump (anaerobic power) were performed.
\end{abstract}

As a result; it was found out that those who did sports in adolescent period had higher physical and physiological parameters than sedentaries.

Keywords: Wrestling; Handball; Sedentary; Physical Characteristic; Physiological Characteristic

(Extended English abstract is at the end of this document)
Özet

$\mathrm{Bu}$ çalışmanın amac1, 13-15 yaş erkek sedanter, hentbolcu ve güreşçilerin bazı fiziksel ve fizyolojik özelliklerinin karşılaştırılmasıdır.

Araştırmaya 77 erkek sporcu ve öğrenci (sedanter $=26$, hentbolcu $=26$ ve güreşçi=25) gönüllü olarak katılmıştır. Çalışmaya katılan deneklerin boy, vücut ağırlı̆̆ (BKI) ölçülmüş ve sağ ve sol el-pençe kuvvetleri, sırt-bacak kuvveti, 20 m. sürat, 30 sn. mekik, 30 sn. şınav, otur-uzan (esneklik), solunum fonksiyon (FVC, VC, $\mathrm{FEV}_{1}, \mathrm{PEF}$ ) değerleri ve dikey sıçrama (anaerobik güç) testleri uygulanmiştır.

Sonuç olarak; adölesan dönemdeki spor yapan bireylerin fiziksel ve fizyolojik parametrelerinin aynı yaştaki sedanter bireylerden daha yüksek olduğu tespit edilmiştir.

Anahtar Kelimeler: Güreș; Hentbol; Sedanter; Fiziksel Özellik; Fizyolojik Özellik

\footnotetext{
${ }^{1}$ Teacher, High school of Atatürk Regional Boarding, Divriği, Sivas, omeralici5@hotmail.com

2 Assoc. Prof. Dr., School of Physical Education and Sports, Niğde University, Niğde, ruchaniri@nigde.edu.tr
} 
Alıcı O., \& İri R. (2015). 13- 15 yaș arasindaki güreșçiler hentbolcular ve sedanterlerin bazi fiziksel ve fizyolojik parametrelerinin karşilaştirilmasi. International Journal of Human Sciences, 12(1), 1070-1081. doi: $\underline{10.14687 / \text { ijhs.v12i1.3117 }}$

\section{Giriş}

Spor, günümüzde sağlıklı ve dengeli bir hayatın parçası ve en yararlı sosyal etkinlikler den biri olarak kabul edilebilir. Özellikle çocukluk çağında düzenli olarak yapılan sportif etkinlikler, sağlıklı bir fiziksel yapının gelişimi ve devamı için önemli rol oynar. Çocuğun dengeli ve sağlıklı gelişiminde düzenli spor yapmanın önemli bir yeri vardır. Her çocuk sağlıklı büyüme ve gelişme göstermek için belirli bir fiziksel aktivite içinde olmalıdır (Açıkada ve Ergen, 1990).

Fiziksel aktivite ve spor yapma şekillerinin maksimum seviyeye çıktı̆̆ son yıllarda; spor biliminin gelişmesi ile birlikte yarışma ve maç sonuçlarını çok küçük farklar belirlemektedir. Bu küçük farkların sonucu belirlemesinde en önemli etmen sporcuların fiziksel ve fizyolojik özellikleridir. Fiziksel ve fizyolojik özelliklerin ergenlik ve ergenlik öncesi döneminde belirlenerek uygun spor branşına yönlendirilmesi başarılı sporcu yetiştirmede birçok katkı sağlayacaktır. Yapılan fiziksel ve fizyolojik uygunluk test çalışmaları daha çok erken yaşları kapsamaktadır. Çocukların erken yaşta fiziksel, fizyolojik özelliklerin ve antropometrik yapılarının belirlenmesi, ülkelerin spor planlarının belirlenmesinde önemli bir yere sahiptir. Erken yaşta yapılan fiziksel ve fizyolojik testler yetenek seçimi konusunda da çocuklarımızı doğru branşa yönlendirme açısından bize yardımcı olacaktır. Özellikle Adölesan dönem; insanda büyüme ve gelişmenin en hızlı olduğu, çocukluktan erişkinliğe geçişi kapsayan özel bir dönemdir (Pekcan, 2004).

Yapılan çalışmalar genellikle aynı yaş grubu çocuklarda sedanterler ile spor yapanların karşılaştırılması ile yapılmış ve sporun organizma üzerinde etkisini ortaya koymuştur. Hatta adölesan dönemdeki sporcular aynı yaş gurubunda olmalarına rağmen, farklı spor branşları ile uğraştıklarından farklı enerji gereksinimleri, fiziksel ve fizyolojik özellikler göstermektedir. Bu bakımdan aynı yaş grubunda olmalarına rağmen farklı spor branşı ile uğraşan adölesan dönemdeki sporcuların bazı fiziksel ve fizyolojik özelliklerinin karşılaştırılması önem taşımaktadır.

Yapılan bu çalışmada da 13-15 yaş erkek sedanter, hentbolcu ve güreşçilerin bazı fiziksel ve fizyolojik özelliklerinin karşılaştırılması amaçlanmıştur.

\section{Materyal Metot}

Katılımcılar: Bu araştırmaya, yaşları 13-15 arasında değişen Sivas Ahmet Ayık güreş eğitim merkezin de yatılı olarak kalan 25 erkek güreşçi, Sivas ilinde bulunan Sağlık Spor Kulübünden 26 erkek hentbolcu ve Sivas Divriği Atatürk YİBO da yatılı olarak kalan düzenli olarak spor yapmayan (sedanter) 26 erkek olmak üzere toplam 77 erkek öğrenci katılmıştır.

\section{Fiziksel ve Fizyolojik Ölçümler:}

Boy ve Vücut Ağırlığı: Sporcuların vücut ağırlığı ve boy uzunlukları SECA marka stadiometre kullanılarak şortlu, tişörtlü ve çıplak ayaklı olarak ölçülmüştür. 
Alıcı O., \& İri R. (2015). 13- 15 yaş arasindaki güreşçiler hentbolcular ve sedanterlerin bazi fiziksel ve fizyolojik parametrelerinin karşilaştirilmasi. International Journal of Human Sciences, 12(1), 1070-1081. doi: $10.14687 /$ ijhs.v12i1.3117

Sağ ve Sol El Pençe Kuvveti: Sporcuların sağ ve sol el-penç kuvvetleri “Takei Grup-D” marka el dinamometresi ile ölçüldü.

Sirt-Bacak Kuvveti: Sporcuların sırt bacak kuvveti “TAKEI BACK- D” marka sirt- bacak dinamometresi ile ölçüldü.

20 m. Sürat Koşusu: 20 m. sürat ölçümleri ise "New Test 2000" Fotosel Cihazı ile yapıldı.

30 sn. Mekik: Çalışmaya katılan sporcu ve öğrencilerden bir cimnastik minderinin üzerine dizleri 90 derece bükülü sırt üstü yatmaları istendi, 'Hazır!', 'Başla!' komutu ile mekik hareketini 30 sn. boyunca maksimum hızda tekrarladılar ve adet olarak yaptığı mekik sayısı kayıt edildi.

30 sn. Şınav: Çalışmaya katılan sporcu ve öğrenciler bir cimnastik minderinin üzerine yüz üstü yatarlar. 'Hazır!' 'Başla!', komutu ile şınav hareketini 30 sn. boyunca maksimum hızda tekrarladılar ve adet olarak yaptığı şınav sayısı kayıt edildi.

Esneklik (Otur-Uzan) Testi: Çalışmaya katılan sporcu ve öğrenciler yere oturup çıplak ayak tabanını düz bir şekilde test sehpasına dayadı. Uzanabildiği kadar öne doğru uzanan denekler testi üç defa tekrar etmişler ve en yüksek olan değer $\mathrm{cm}$. cinsinden kayıt edildi.

Solunum Fonksiyon Testleri: Çalışmaya katılan sporcu ve öğrencilerin solunum fonksiyon testleri Chestograph HI-105 spirometre ile test edildi.

Dikey Sıçrama: Elektronik sıçrama aleti Jump-metre ile ölçüldü. Kaydedilen sıçrama mesafesi Lewis formülü uygulanarak anaerobik güç (kg-m/sn.) değeri hesaplandı.

$$
\begin{aligned}
& \mathrm{P}=\sqrt{ } 4.9 \text { (A ğıllık) } \sqrt{\mathrm{D}(\mathrm{m}),} \\
& \mathrm{P}=\mathrm{Güç} \\
& \mathrm{D}=\text { Dikey siçrama mesafesi (m.) }
\end{aligned}
$$

Verilerin Toplanması: Çalısmada yer alacak sporcu ve öğrencilere, araştırmanın amacı ve önemi ile ilgili açıklama yapıldıktan sonra test protokolleri ve testlere girmeden önce yapılması gerekenler hakkında bilgi verildi. Çalısmaya katılan sporcu ve öğrencilerin, velileri ve antrenörlerinden test için izin alındı.

Ayrıca çalışmada uygulanılan tüm alan ve saha testleri protokollere uygun olarak yapılmıştur.

Verilerin İstatistiksel Analizi: Elde edilen verilerin SPSS 18.0 programı ile analiz edildiği araştırmada gruplar arası karşılaştırmalar tek yönlü varyans analizi (One way ANOVA) ile değerlendirilirken, gruplar arası farklılıkların hangi grup yada gruplardan kaynaklandığının tespiti için çoklu karşılaştırma testlerinden Tukey testi kullanılmışır. 
Alıcı O., \& İri R. (2015). 13- 15 yaș arasindaki güreșçiler hentbolcular ve sedanterlerin bazi fiziksel ve fizyolojik parametrelerinin karşilaştirilmasi. International Journal of Human Sciences, 12(1), 1070-1081. doi: 10.14687/ijhs.v12i1.3117

\section{Bulgular}

Tablo 1: Katılımcıların Demografik Özelliklerine İlişkin Bilgiler

\begin{tabular}{|c|c|}
\hline $\mathrm{N}=77$ & Ortalama \pm Standart Sapma \\
\hline Yaş (yil) & $13,95 \pm 0,81$ \\
\hline Boy $(\mathrm{m})$ & $1,59 \pm 1,10$ \\
\hline Vücut Ağırlığı (kg) & $52,00 \pm 12,32$ \\
\hline Beden Kitle İndeksi $\left(\mathrm{kg} / \mathrm{m}^{2}\right)$ & $20,33 \pm 2,90$ \\
\hline
\end{tabular}

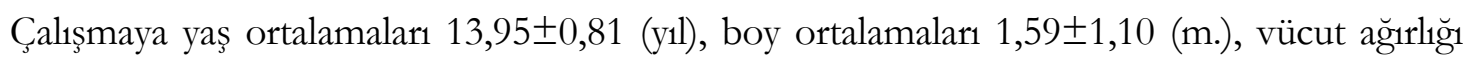

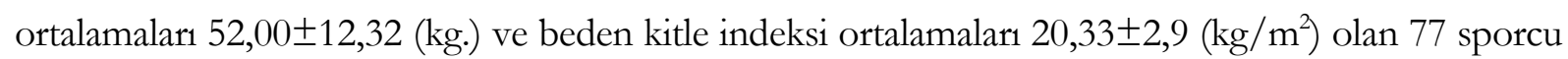
ve öğrenci katılmıştır.

Tablo 2: Katılımcıların Demografik Özelliklerinin Karşılaştırılması

\begin{tabular}{|c|c|c|c|c|c|}
\hline Değişkenler & Branş & $\mathbf{N}$ & $\bar{X} \pm$ S.S. & $\mathbf{F}$ & $\mathbf{P}$ \\
\hline \multirow{3}{*}{ Yaş (y1l) } & Sedanter & 26 & $13,92 \pm 0,84$ & \multirow{3}{*}{0,018} & \multirow{3}{*}{0,982} \\
\hline & Güreşçi & 25 & $13,96 \pm 0,79$ & & \\
\hline & Hentbolcu & 26 & $13,96 \pm 0,82$ & & \\
\hline \multirow{3}{*}{ Boy Uzunluğu (m.) } & Sedanter & 26 & $1,56 \pm 1,10$ & \multirow{3}{*}{1,719} & \multirow{3}{*}{0,186} \\
\hline & Güreşçi & 25 & $1,61 \pm 1,00$ & & \\
\hline & Hentbolcu & 26 & $1,60 \pm 1,00$ & & \\
\hline \multirow{3}{*}{ Vücut Ağ̀1rlığı (kg.) } & Sedanter & 26 & $47,58 \pm 12,54$ & \multirow{3}{*}{2,638} & \multirow{3}{*}{0,078} \\
\hline & Güreşçi & 25 & $54,15 \pm 11,49$ & & \\
\hline & Hentbolcu & 26 & $54,35 \pm 12,10$ & & \\
\hline \multirow{3}{*}{$\begin{array}{c}\text { Beden Kitle } \\
\text { İndeksi }\left(\mathrm{kg} / \mathrm{m}^{2}\right)\end{array}$} & Sedanter & 26 & $19,29 \pm 2,90$ & \multirow{3}{*}{2,725} & \multirow{3}{*}{0,720} \\
\hline & Güreşçi & 25 & $20,70 \pm 2,68$ & & \\
\hline & Hentbolcu & 26 & $21,02 \pm 2,80$ & & \\
\hline
\end{tabular}

Tablo 2’de Sedanterler, Güreşçiler ve Hentbolcuların demografik özelliklerinden yaş (yıl), boy (m.), vücut ağırlı̆̆ı (kg.) ve beden kitle indeksleri $\left(\mathrm{kg} / \mathrm{m}^{2}\right)$ arasındaki farklılık incelendiğinde istatistiksel olarak anlamlı bir farklılık olmadığı tespit edilmiştir ( $p>0,05)$.

Tablo 3: Katılımcıların Fiziksel ve Fizyolojik Özelliklerinin Karşılaştırılması

\begin{tabular}{|c|c|c|c|c|c|}
\hline Değişkenler & Branş & $\mathbf{N}$ & $\bar{X} \pm$ S.S. & $\mathbf{F}$ & $\mathbf{P}$ \\
\hline \multirow{3}{*}{$\begin{array}{c}\text { Sağ E1 Kavrama } \\
\text { (kg.) }\end{array}$} & Sedanter & 26 & $22,36 \pm 8,35^{b}$ & \multirow{3}{*}{11,990} & \multirow{3}{*}{$0,000 * * * *$} \\
\hline & Güreşçi & 25 & $32,88 \pm 7,08^{a}$ & & \\
\hline & Hentbolcu & 26 & $30,50 \pm 8,66^{\mathrm{a}}$ & & \\
\hline \multirow{3}{*}{$\begin{array}{l}\text { Sol E1 Kavrama } \\
\text { (kg.) }\end{array}$} & Sedanter & 26 & $20,73 \pm 8,20^{\mathrm{b}}$ & \multirow{3}{*}{17,752} & \multirow{3}{*}{$0,000 * * *$} \\
\hline & Güreşçi & 25 & $33,29 \pm 6,73^{a}$ & & \\
\hline & Hentbolcu & 26 & $30,10 \pm 8,47 a$ & & \\
\hline \multirow{3}{*}{$\begin{array}{c}\text { S1rt-Bacak } \\
\text { Kuvveti } \\
\text { (kg.) }\end{array}$} & Sedanter & 26 & $56,37 \pm 18,57^{b}$ & \multirow{3}{*}{15,677} & \multirow{3}{*}{$0,000 * * *$} \\
\hline & Güreșçi & 25 & $87,08 \pm 23,88^{a}$ & & \\
\hline & Hentbolcu & 26 & $79,48 \pm 18,64^{a}$ & & \\
\hline \multirow{2}{*}{20 m. Sürat (sn.) } & Sedanter & 26 & $4,00 \pm 0,30^{\mathrm{a}}$ & \multirow{2}{*}{37,007} & \multirow{2}{*}{$0,000 * * *$} \\
\hline & Güreşçi & 25 & $3,41 \pm 0,22^{\mathrm{b}}$ & & \\
\hline
\end{tabular}


Alıcı O., \& İri R. (2015). 13- 15 yaș arasindaki güreșçiler hentbolcular ve sedanterlerin bazi fiziksel ve fizyolojik parametrelerinin karşilaştirilmasi. International Journal of Human Sciences, 12(1), 1070-1081. doi: $10.14687 /$ ijhs.v12i1.3117

\begin{tabular}{|c|c|c|c|c|c|}
\hline & Hentbolcu & 26 & $3,56 \pm 0,23^{\mathrm{b}}$ & & \\
\hline \multirow{3}{*}{30 sn. Mekik } & Sedanter & 26 & $17,85 \pm 3,86^{c}$ & \multirow{3}{*}{67,952} & \multirow{3}{*}{$0,000 * * *$} \\
\hline & Güreşçi & 25 & $31,44 \pm 3,95^{a}$ & & \\
\hline & Hentbolcu & 26 & $26,69 \pm 4,81^{\mathrm{b}}$ & & \\
\hline \multirow{3}{*}{30 sn. Şınav } & Sedanter & 26 & $16,15 \pm 6,56^{b}$ & \multirow{3}{*}{101,251} & \multirow{3}{*}{$0,000 * * *$} \\
\hline & Güreşçi & 25 & $39,96 \pm 3,83^{a}$ & & \\
\hline & Hentbolcu & 26 & $27,27 \pm 6,96^{\mathrm{a}}$ & & \\
\hline \multirow{3}{*}{$\begin{array}{l}\text { Otur- Uzan } \\
\text { Esneklik } \\
\text { (cm.) }\end{array}$} & Sedanter & 26 & $17,77 \pm 6,78^{b}$ & \multirow{3}{*}{17,750} & \multirow{3}{*}{$0,000 * * *$} \\
\hline & Güreşçi & 25 & $26,28 \pm 5,84^{a}$ & & \\
\hline & Hentbolcu & 26 & $25,92 \pm 4,58^{a}$ & & \\
\hline \multirow{3}{*}{$\begin{array}{c}\mathrm{FEV}_{1} \\
\text { (lt./sn.) }\end{array}$} & Sedanter & 26 & $2,64 \pm 0,67$ & \multirow{3}{*}{1,508} & \multirow{3}{*}{0,228} \\
\hline & Güreşçi & 25 & $2,93 \pm 0,66$ & & \\
\hline & Hentbolcu & 26 & $2,86 \pm 0,58$ & & \\
\hline \multirow{3}{*}{$\begin{array}{l}\text { FVC } \\
\text { (lt.) }\end{array}$} & Sedanter & 26 & $2,81 \pm 0,74^{b}$ & \multirow{3}{*}{4,180} & \multirow{3}{*}{ 0,019* } \\
\hline & Güreşçi & 25 & $3,32 \pm 0,72^{a}$ & & \\
\hline & Hentbolcu & 26 & $3,24 \pm 0,62^{\mathrm{a}}$ & & \\
\hline \multirow{3}{*}{$\begin{array}{l}\text { VC } \\
\text { (lt.) }\end{array}$} & Sedanter & 26 & $2,84 \pm 0,74^{b}$ & \multirow{3}{*}{4,736} & \multirow{3}{*}{$0,012 *$} \\
\hline & Güreşçi & 25 & $3,44 \pm 0,83^{a}$ & & \\
\hline & Hentbolcu & 26 & $3,38 \pm 0,73^{a}$ & & \\
\hline \multirow{3}{*}{$\begin{array}{l}\text { PEF } \\
\text { (lt.) }\end{array}$} & Sedanter & 26 & $317,73 \pm 66,97$ & \multirow{3}{*}{0,080} & \multirow{3}{*}{0,923} \\
\hline & Güreşçi & 25 & $320,60 \pm 77,07$ & & \\
\hline & Hentbolcu & 26 & $312,88 \pm 64,19$ & & \\
\hline \multirow{3}{*}{$\begin{array}{l}\text { Dikey Siçrama } \\
\text { (cm) }\end{array}$} & Sedanter & 26 & $36,00 \pm 4,98^{b}$ & \multirow{3}{*}{32,871} & \multirow{3}{*}{$0,000 * * *$} \\
\hline & Güreşçi & 25 & $43,08 \pm 3,90^{a}$ & & \\
\hline & Hentbolcu & 26 & $43,28 \pm 2,98^{a}$ & & \\
\hline \multirow{3}{*}{$\begin{array}{c}\text { Anaerobik Güç } \\
\text { (kg.m/sn) }\end{array}$} & Sedanter & 26 & $63,06 \pm 16,02^{b}$ & \multirow{3}{*}{7,269} & \multirow{3}{*}{$0,001 * *$} \\
\hline & Güreşçi & 25 & $78,55 \pm 17,46^{a}$ & & \\
\hline & Hentbolcu & 26 & $78,67 \pm 18,27 a$ & & \\
\hline
\end{tabular}

${ }^{*} \mathrm{p}<0,05,{ }^{* *} \mathrm{p}<0,01,{ }^{* * *} \mathrm{p}<0,001$, abc: Gruplar arasındaki farklılığ farklı harfler temsil etmektedir.

Tablo 3'de Sedanterler, Güreşçiler ve Hentbolcuların fiziksel ve fizyolojik özellikleri karşılaştırıldığında; FEV ${ }_{1}$ ve PEF değerleri arasında istatiksel açıdan anlamlı farklılık olmadığı tespit edilirken ( $p>0,05)$, diğer değerler arasında istatistiksel açıdan anlamlı farklılık olduğu tespit edilmiştir $(\mathrm{p}<0,05)$.

\section{Tartişma Sonuç}

Bu çalışma, 13-15 yaş erkek sedanter, hentbolcu ve güreşçilerin bazı fiziksel ve fizyolojik Özelliklerinin karşılaştırılması amacı ile yapılmıştır.

Araştırmada kattlımcıların demografik bilgileri (Yaş, Boy, Vücut Ağıllığı, BKİ) arasında yapılan fark testinde istatistiksel açıdan anlamlı farklılık olmadığı tespit edilmiştir $(\mathrm{p}>0,05)$. Bu durum çalışma grubumuzun domografik bilgiler açısından homojen olduğunu ve demografik bilgiler açısından farklılık olmayan bir grupta bulunan bazı fiziksel ve fizyolojik farklılıkların çalışma grubundaki sporcu ve öğrencilerin yapmış oldukları egzersizden kaynaklandığını düşündürmektedir. 
Alıcı O., \& İri R. (2015). 13- 15 yaş arasindaki güreşçiler hentbolcular ve sedanterlerin bazi fiziksel ve fizyolojik parametrelerinin karşilaştirilmasi. International Journal of Human Sciences, 12(1), 1070-1081. doi: $10.14687 /$ ijhs.v12i1.3117

Yapılan bu çalışmada gruplar arası sağ ve sol el pençe kuvvetleri farkı incelendiğinde; hem sağ hemde sol el-pençe kuvvetleri açısından güreşçi ve hentbolcular arasında istatistiksel açıdan anlamlı farklılık bulunmazken ( $\mathrm{p}>0,05)$, hem güreşçi hemde hentbolcuların sedanterler ile arasında istatiksel açıdan anlamlı farklılık olduğu tespit edilmiştir $(\mathrm{p}<0,001)$.

Savucu ve arkadaşları, (2004) yapmış oldukları çalışmada yaş ortalamaları 15,33 $\pm 0,47$ yıl olan 36 yıldız basketbolcunun sağ el kavrama kuvveti ölçüm değeri ortalamasını 49,011 44,125 kg olarak, sol el kavrama kuvveti ölçüm değeri ortalamasını 46,755£5,430 kg olarak tespit etmişlerdir.

Kılınç ve arkadaşları, (2002) Kütahya'da 3/4 Temmuz 1999 yılında “Türk Cumhuriyetleri ve Toplulukları ile Türk Güreş Eğitim Merkezleri 8.Yıldızlar Güreş Turnuvasına” katılan yıldız serbest milli takım adaylarından 24 güreşçinin sol pençe kuvvetini ortalama 42,37+9,25 kg sağ pençe kuvvetini ortalama 40,87+8,49 kg olarak bulmuştur.

Kızılakşam, (2006) yaptı̆̆ı çalışmada 12-14 yaş grubu aktif spor yapmayan erkek

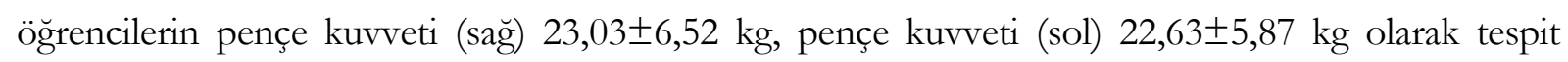
etmiştir.

Çalışma grubunun sırt-bacak kuvvetleri arası farklılığa bakıllığında güreşçi ve hentbolcular arasında istatistiksel açıdan anlamlı farklılık bulunmazken ( $>>0,05)$, hem güreşçi hemde hentbolcuların sedanterler ile arasında istatiksel açıdan anlamlı farklılık olduğu tespit edilmiştir $(\mathrm{p}<0,001)$.

Polat ve arkadaşları, (2009) yapmış oldukları çalışmada 16 yaşındaki 34 futbolcunun sırt

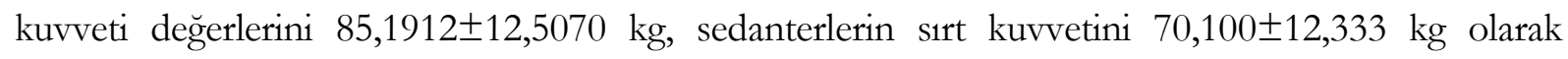
bulmuşlardır.

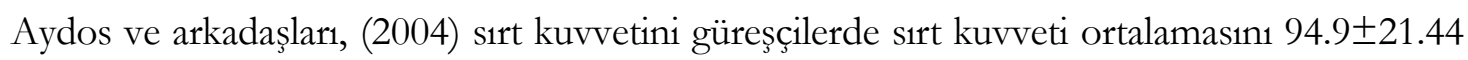
$\mathrm{kg}$, olarak bulmuşlardır.

Güreş sporunda kuvvet önemli bir motorik özelliktir. Güreş sporunda sırt ve bacak kuvveti geliştirmeye yönelik antrenmanlar yoğun olarak yapılmaktadır. Bundan dolayı güreşçilerin sırt ve bacak kuvveti sayısal olarak hem hentbolcular hem de istatistiksel olarak sedanterlerden yüksek olması beklenen bir sonuçtur.

Güreş branşında itme, çekme, kaldırma ve kavrama gibi hareketlerin yoğun olması ve fazla kuvvet gerektirmesinden dolayı antrenman dönemlerinde bu bölgelere yönelik çalışmaların yoğun yapılmasının bu sonuçta etkili bir faktör olduğunu düşündürmektedir.

Literatürde $20 \mathrm{~m}$ sprint koşuları özel süratin gösterge olarak belirtilmektedir. Kuru ve Savaş, (2006) üst düzey erkek yaş ortalamaları 22.0 3.95 olan 12 elit erkek basketbolcunun bazı fiziksel ve fizyolojik parametrelerinin incelenmesi isimli araştırmalarında sporcu grubunun hazırlık donemi 
Alıcı O., \& İri R. (2015). 13- 15 yaş arasindaki güreşçiler hentbolcular ve sedanterlerin bazi fiziksel ve fizyolojik parametrelerinin karşilaştirilmasi. International Journal of Human Sciences, 12(1), 1070-1081. doi: $10.14687 /$ ijhs.v12i1.3117

öncesi 20 metre surat değerini hazırlık donemi öncesi; 3.03 sn. hazırlık donemi sonrası; 2.92 sn. olarak bulmuşlardır.

Eler ve arkadaşlanı, (1999) Türkiye 1. Hentbol liginde sporcu olarak yer alan, yaş ortalaması 24.0 \pm 3.70 olan 15 sporcu ile yaptı̆ı araştırmasında sezon öncesi ve sezon sonrası $30 \mathrm{~m}$. sprint değerini sırasıyla; $4.36 \pm 0.12,4.30 \pm 0.11 \mathrm{sn}$. olarak bulmuştur.

Çalışmamızda da $20 \mathrm{~m}$. sürat değerleri arası farklılığa bakıldığında güreşçi ve hentbolcular arasında istatistiksel açıdan anlamlı farklılık bulunmazken ( $>0,05)$, hem güreşçi hemde hentbolcuların sedanterler ile arasında istatiksel açıdan anlamlı farklılık olduğu tespit edilmiştir $(\mathrm{p}<0,001)$.

Cvetkoviç ve arkadaşları, (2005) 16-20 yaş arası Hırvat güreşçisinin ( $\mathrm{n}=72) 30$ sn. mekik ortalama derecesini 26,82 $\pm 12,20$ tekrar olarak elde etmişlerdir.

Cicioğlu ve arkadaşları, (2007) 15-17 yaş grubu güreşçilerdeki 30 sn. mekik parametresinin sezonsal değişimini incelemek amacı ile yapmış olduğu çalışmada sezon öncesi 30 sn. mekik ortalamalarını 30,76 $\pm 4,12$ bulurken, sezon sonu 30 sn. mekik ortalamalarını $40.36 \pm 3.09$ olarak elde etmişlerdir.

Arabacı, (2003) da 15-16 yaş güreşçilerin özel hazırlık döneminde 30 sn. mekik testlerinde 27,01£2,0 tekrar sayısı elde etmiştir.

Çalışmaya katılan sporcu ve öğrenci gruplarında 30 sn. mekik ve şınav değerleri arası farklılı̆ga bakıldığında güreşçi ve hentbolcular arasında istatistiksel açıdan anlamlı farklılık bulunmazken $(\mathrm{p}>0,05)$, hem güreşçi hem de hentbolcuların sedanterler ile arasında istatiksel açıdan anlamlı farklılık olduğu tespit edilmiştir $(\mathrm{p}<0,001)$.

Sporun sürat çabukluk gibi motorik özellikleri geliştirdiği yapılan çalışmalar ile ortaya konmuştur. Spor yapan bireyler ile spor yapmayan bireyler arasında oluşan farkın buradan kaynaklandığ1 düşünülmektedir. Güreşçiler ile hentbolcular arasında istatistiksel açıdan fark bulunmasa da aralarında oluşan sayısal farkın yapmış oldukları spor branşının motorik özelliklerinden kaynaklandığı ve güreşçilerin genellikle her antrenman sonrası tamamlayıcı kuvvet çalışmalarında şınav ve mekik yaptıklarından kaynaklandığı düşünülmektedir.

Çalışmamıza katılan sporcu ve öğrenci gruplarında otur-uzan (esneklik) değerleri arası farklılı̆ga bakıldığında güreşçi ve hentbolcular arasında istatistiksel açıdan anlamlı farklılık bulunmazken ( $p>0,05)$, hem güreşçi hem de hentbolcuların sedanterler ile arasında istatiksel açıdan anlamlı farklılık olduğu tespit edilmiştir $(\mathrm{p}<0,001)$.

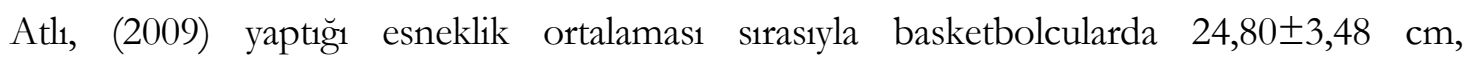
futbolcularda $18,25 \pm 2,14 \mathrm{~cm}$, sedanterlerde $15,65 \pm 2,25 \mathrm{~cm}$ olarak tespit etmiştir. 
Alıcı O., \& İri R. (2015). 13- 15 yaş arasindaki güreşçiler hentbolcular ve sedanterlerin bazi fiziksel ve fizyolojik parametrelerinin karşilaştirilmasi. International Journal of Human Sciences, 12(1), 1070-1081. doi: $10.14687 /$ ijhs.v12i1.3117

Ateş ve arkadaşları, (2007) tarafindan yaşları 14-16 arasında değişen 12 futbolcu ile yapılan

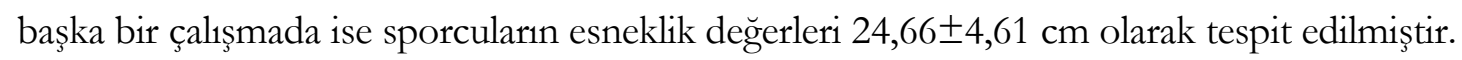

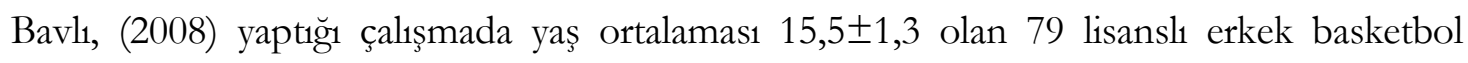

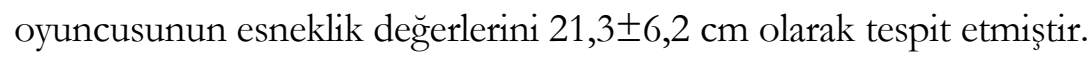

Güreşçilerin esnekliklerinin yüksek olmasında, güreşte esnekliğin diğer branşlardan daha ön planda olması ve her antrenman öncesi esneklik geliştirici cimnastik hareketleri ile ısınma yaptıklarından kaynaklandığı düşünülmektedir. Çalışmamız literatürde yapılan çalışmalarla bu bağlamda paralellik göstermektedir.

Çalışmamıza katılan sporcu ve öğrenci gruplarında ise solunum parametrelerinden $\mathrm{FEV}_{1}$, FVC, VC ve PEF değerleri ölçülmüştür. Gruplar arası FVC ve VC değerleri arasında istatistiksel açıdan anlamlı farklılık tespit edilirken $(p<0,05), F_{1}$ ve PEF değerleri arasında istatiksel açıdan anlamlı farklılık olmadığı tespit edilmiştir ( $\mathrm{p}>0,05)$.

Wells ve arkadaşları, (2002) çalışmalarında 12-15 yaş aralığındaki 34 yüzücünün yarısına ekspiratör kas antrenmanı uygulamışlar ve bu antrenmanı yapan 17 yüzücünün $\mathrm{FEV}_{1}$ değerlerinin bu antrenmanı yapmayan gruba göre arttığını tespit etmişlerdir.

Kubiak ve Janczaruk, (2005) 12- 14 yaş 310 elit yüzücü ile yaptıkları 6 aylık çalışma sonucunda $\mathrm{VC}, \mathrm{FVC}, \mathrm{FEV}_{1}$ parametrelerinin ön test ve son test değerleri arasında istatistiksel olarak anlamlı fark bulmuşlardır.

Taşgın ve Dönmez, (2009) çalışmalarında 10-16 yaş grubundaki sporcu olmayan (sedanter) çocuklarda 3 ay boyunca uygulanan antrenman programının solunum parametrelerinden FVC, $\mathrm{FEV}_{1}, \mathrm{PEF}$, üzerindeki etkilerini araştırmışlar ve egzersizin $\mathrm{FVC}$ ve $\mathrm{FEV}_{1}$ değerleri üzerine etkisinin olmadığını belirtmişlerdir.

İri, (2000) yapmış olduğu araştırmada makro dönem antrenman programı sonrası futbolcuların FVC değerlerini 5.44+0.43 (lt), olarak tespit etmiştir.

Buna göre yapılan antrenmanların solunum fonksiyonlarını geliştirdiği hatta antrenman şiddetine bağlı olarak solunum fonksiyon parametrelerinin arttığı düşünülmektedir.

Ateş ve arkadaşları, (2007) yapmış oldukları çalışmada yaşları 14-16 arasında değişen 12

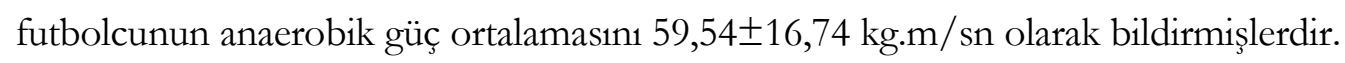

Sofi, (2002) Kırıkkale Çelikspor Kulübü alt yapısından 16 yıldız futbolcunun anaerobik güç ortalamasın 105,65 $\pm 2,81 \mathrm{~kg} . \mathrm{m} / \mathrm{sn}$ olarak bildirilmiştir

Cicioğlu ve arkadaşlan, (2007) 15-17 yaş grubu güreşçilerin anaerobik kapasite sezon öncesi

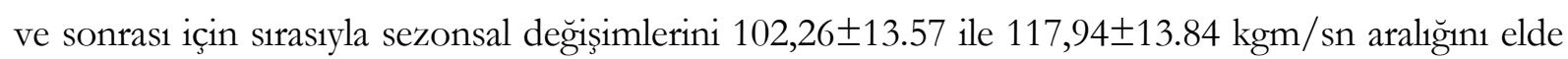
etmişlerdir. 
Alıcı O., \& İri R. (2015). 13- 15 yaş arasindaki güreşçiler hentbolcular ve sedanterlerin bazi fiziksel ve fizyolojik parametrelerinin karşilaştirilmasi. International Journal of Human Sciences, 12(1), 1070-1081. doi: $10.14687 /$ ijhs.v12i1.3117

Atlı, (2009) yaptı̆̆ çalışmada anaerobik güç ortalaması sırasıyla basketbolcularda $119,97 \pm 10,80 \mathrm{~kg} \cdot \mathrm{m} / \mathrm{sn}$, futbolcularda $95,31 \pm 10,78 \mathrm{~kg} \cdot \mathrm{m} / \mathrm{sn}$, sedanterlerde $96,42 \pm 16,89 \mathrm{~kg} \cdot \mathrm{m} / \mathrm{sn}$ olarak tespit etmiştir.

Çalışmamızda da sporcu ve öğrencilerin dikey sıçrama mesafeleri ve Lewis formülü kullanılarak grupların anaerobik güçleri hesaplanmıştır. Dikey sıçrama değerleri ve anaerobik güçleri arası farklılığa bakıldığında güreşçi ve hentbolcular arasında istatistiksel açıdan anlamlı farklılık bulunmazken ( $p>0,05)$, hem güreşçi hem de hentbolcuların sedanterler ile arasında istatiksel açıdan anlamlı farklılık olduğu tespit edilmiştir $(\mathrm{p}<0,001)$.

Çalışmamız literatürde yer alan çalışmalarla paralellik göstermektedir. Sporun organizma üzerindeki etkileri herkes tarafindan bilinen bir gerçektir. Yine motorik özelliklerde ortaya konan farklılıklarda egzersizin etkisi olduğu bulgularımızla sabittir. Hatta spor yapan bireyler arasinda bile genel dönemden özel döneme geçiş çağı olan adolesan dönemde sporcuların branşlarına özel parametrelerinin geliştiği istatistiksel açıdan farklılık olarak ortaya konulmasa da sayısal olarak tespit edilmiştir.

Bu bağlamda spor branşlarının sedanterlere oranla farklı motorik özellikleri geliştirdiği ve diğer spor branşlarının arasında oluşan sayısal farklılığında spor branşlarına ait antropometrik yapılarına, somatotiplerine ve kullanmış oldukları enerji kaynaklanı farklılığından kaynaklandığı düşünülmektedir.

Bu bilgiler doğrultusunda, adolesan dönemindeki spor yapan bireylerin fiziksel ve fizyolojik parametrelerinin aynı yaştaki sedanter bireylerden daha yüksek olduğu tespit edilmiştir. Yine bu sonuca bağlı olarak adolesan dönemde bireyleri branş gözetmeksizin spora yönlendirilerek fiziksel ve fizyolojik özelliklerinin geliştirilmesi gerekliliği önem arz etmektedir.

\section{Kaynaklar}

Açıkada, C., Ergen, E. (1990), Bilim ve Spor, (1.Baskı), Ankara: Büro Tek Ofset Matbaacıllk.

Arabacı R. (2003), “15-16 Yaş Grubu Güreşçilerine Uygulanan Model Antrenman Programının Kuvvet Ve Dayanıklılığın Gelişimi Üzerine Etkisinin Araştırılması” Bed. Eğt. Ve Spor Bil. Dergisi: 5 (2); 15-22

Ateş, M., Demir, M., Ateşoğlu, U. (2007), "Pliometrik Antrenmanın 16-18 Yaş Grubu Erkek Futbolcuların Bazı Fiziksel ve Fizyolojik Parametreleri Üzerine Etkisi” Niğde Üniversitesi Beden Eğitimi ve Spor Bilimleri Dergisi, Cilt 1, Say1 1 : 1-12.

Atlı, A. (2009), "14-16 Yaşları Arasındaki Erkek Basketbolcu, Futbolcu ve Sedanterlerin Bazı Fiziksel, Fizyolojik ve Antropometrik Özelliklerinin Karşılaştırılması” YüksekLisans Tezi, Selçuk Üniversitesi, Sağllk Bilimleri Enstitüsü, Konya. 
Alıcı O., \& İri R. (2015). 13- 15 yaş arasindaki güreşçiler hentbolcular ve sedanterlerin bazi fiziksel ve fizyolojik parametrelerinin karşilaştirilmasi. International Journal of Human Sciences, 12(1), 1070-1081. doi: $10.14687 /$ ijhs.v12i1.3117

Aydos, L.,Pepe, H., Karakuş, H. (2004), "Bazı Takım ve Ferdi Sporlarda Rölatif Kuvvet Değerlerinin Araştırilması," Ahi Evran Üniversitesi, Kırşehir EğitimFakültesi Dergisi (Kefad), Cilt 5, Say1 2 : 305-315.

Bavlı, Ö. (2008), “Adolesan Dönem Basketbolcularda Mevkilere Göre Yapısal ve Motorik Özelliklerin Karşılaştrrılması,” Niğde Üniversitesi Beden Eğitimi Ve Spor Bilimleri Dergisi, Cilt 2, Say1 3, :1 74-181.

Cicioğlu, İ., Kürkçü, R., Eroğlu, H., \& Yüksek, S. (2007), 15-17 Yaş Grubu Güreşçilerin Fiziksel Ve Fizyolojik Özelliklerinin Sezonsal Değişimi. Spormetre Beden Eğitimi Ve Spor Bilimleri Dergisi, 4, 151-156.

Cvetković Č., Marić J., Marelić N. (2005), Technical Efficiency of Wrestlers in Relation to Some Anthropometric and Motor Variables. Kinesiology., 37(1): 74-83.

Eler S., Yıldıran İ., Sevim Y., (1999) “Bir Sezonluk Antrenman Periyotlaması Boyunca Üst Düzey Erkek Hentbolcuların Bazı Motorik Ve Fizyolojik Parametrelerinin İncelenmesi” Gazi Beden Eğitimi ve Spor Bilimleri Dergisi, Cilt:4,Sayı:3, s.25 34.

İri, R. (2000), “Amatör Futbolcularda Makro Dönem Dayanıkllık Antrenmanının Aerobik, Anaerobik Kapasite ve Dolaşım, Solunum Sistemlerine Etkisi”, YüksekLisans Tezi, Sakarya Üniversitesi, Sosyal Bilimler Enstitüsü, Sakarya.

Kulınç, F., Girgin, İ., Erbay, A., Ersoy, A., Bişgin, H. (2002), "VIII. Türk Cumhuriyetleri Turnuvasına Katılan Yıldız Serbest Milli Takım Adaylarının Bazı Fiziksel, Fizyolojik ve Biomotrik Özelliklerinin Belirlenmesi," 7. Uluslararası Spor Bilimleri Kongresi, 27-29 Ekim , Antalya.

Kızılakşam, E. (2006), "Edirne İl Merkezi İlköğretim Okullarındaki 12-14 Yaş Grubu Aktif Olarak Spor Yapan ve Yapmayan (Beden Eğitimi Dersine Giren) Öğrencilerin Eurofit Test Bataryaları Uygulama Sonuçlarının Karşılaştırılması", Yüksek Lisans Tezi, Trakya Üniversitesi, Sağlık Bilimleri Enstitüsü, Edirne.

Kubiak-Janczaruk E. (2005), "Spirometric evaluation of the respiratory system in adolescent swimmers" Ann Acad Med Stetin., 51:105-113.

Kuru C., Savaş S. (2006), Üst Duzey Basketbolcuların Hazırlık Dönemi Süresince Bazı Fiziksel ve Fizyolojik Parametrelerinin İncelenmesi, 9. Uluslararas1 Spor Bilimleri Kongresi (3-5 Kasım 2006, Mugla) Bildiri Kitabı, Muğla, s. 162-164.

Pekcan, G. (2004), “Adolesan Döneminde Beslenme”, Klinik Çocuk Forumu, Cilt 4, Sayı 1 : 38-47.

Polat, Y., Çınar, V., Savucu, Y. Polat, M. (2009), "16 Yaş Gençlerin Fiziksel Uygunluk Düzeylerinin Incelenmesi," e-Journal of New World Sciences Academy Sport Sciences, Volume: 4, Number: 1, : 1-9.

Savucu, Y., Polat, Y., Ramazanoğlu, F., Karahüseyinoğlu, M.F., Biçer, Y.A. (2004), “Alt Yapıdaki Küçük, Yıldız ve Genç Basketbolcuların Bazı Fiziksel Uygunluk Parametrelerinin İncelenmesi”, Firat Üniversitesi, Sağlık Bilimleri Tıp Dergisi Cilt 18, Say1 4 : 205-209.

Sofi, N. (2002), "Futbolda Sezon Öncesi İle Sezon Öncesi Hazırlık Dönemi Sonrasındaki Vücuttaki Bazı Fizyolojik ve Fiziksel Değişikliklerin İncelenmesi”, Yüksek Lisans Tezi, Kırıkkale Üniversitesi, Sağlık Bilimleri Enstitüsü, Kırıkkale.

Taşgın E., Dönmez N. (2009), 10-16 yaş grubu çocuklara uygulanan egzersiz programının solunum parametreleri üzerine etkisi. Selçuk Üniversitesi Beden Eğitimi ve Spor Bilim Dergisi, 11:1316. 
Alıcı O., \& İri R. (2015). 13- 15 yaş arasindaki güreşçiler hentbolcular ve sedanterlerin bazi fiziksel ve fizyolojik parametrelerinin karşilaştirilmasi. International Journal of Human Sciences, 12(1), 1070-1081. doi: $10.14687 /$ ijhs.v12i1.3117

Wells G.D., Plyley M, Thomas S, Goodman L, Duffin J. (2005), "Effects of concurrent inspiratory and expiratory muscle training on respiratory and exercise performance in swimmers" Eur J Appl Physiol. 200:527-540.

\section{Extended English Abstract}

The study aimed at the comparison of some physical and physiological characteristics of the male sedentaries, male handball players and male wrestlers whose ages were between 13 and 15 .

77 male individuals (sedentaries $=26$, handball players $=26$ and wrestler $=25$ ) participated voluntarily in the study and their mean age was $13.95 \pm 0.81$ years, mean height was $158.7 \pm 11 \mathrm{~cm}$, mean weight was $52 \pm 12.32 \mathrm{~kg}$ and mean body mass index was $20.33 \pm 2.9 \mathrm{~kg} / \mathrm{m}^{2}$. Height, weight and BMI values of the subjects were measured and tests for hand grip strength, leg and back strength, $20 \mathrm{~m}$ sprint test, $30 \mathrm{sec}$ sit-up, push-up, sit-reach, respiratory function and counter movement jump were performed.

The data obtained were assessed using SPSS 18.0 program. Descriptive statistical values regarding arithmetic means and standard deviations of demographic characteristic and measurement results of the subjects were calculated. Intergroup comparisons were performed with Oneway ANOVA. Tukey test was employed to find out which group/s provided the intergroup differences. Confidence interval was $95 \%$. Significance level was set $\mathrm{p}<0.05$.

There was statistically significant difference among the participants in terms of hand grip strength, $20 \mathrm{~m}$ sprint test, $30 \mathrm{sec}$ sit-up, push-up, sit-reach, FVC (forced vital capacity), VC (vital capacity) and anaerobic strength $(\mathrm{p}<0.05)$ values while no statistically significant difference existed in terms of $\mathrm{FEV}_{1}$ (forced expiratory volume in 1 second), PEF (peak expiratory flow), age, height, weight and BKI values ( $\mathrm{p}>0.05)$.

In our work, the order of speed measure of 20 meters is : the measure of sedanteries is $4,00 \pm 0,3$ (secs), the measure of wrestlers is $3,41 \pm 0,22$ (secs), and the measure of handball players $3,56 \pm 0,23$. According to discripancy between the groups, there isn't explicit statistical discrepancy between the hanball players and wrestlers $(\mathrm{p}>0,05)$ but there is a consiredable statistical discripancy between the both wrestlers and hanball players and sedantaries $(\mathrm{p}<0,001)$

The order of 30 second shuttle measure of the students and athletes that who participated in our work is : the measure of sedanteries is $17,85 \pm 3,86$ times, the measure of the wrestlers is $31,44 \pm 3,95$ times and the measure of handball players is $26,69 \pm 4,81$ times. According to discripancy between the groups, , there isn't explicit statistical discrepancy between the hanball players and wrestlers $(\mathrm{p}>0,005)$ but there is a consiredable statistical discripancy between the both wrestlers and hanball players and sedantaries $(\mathrm{p}<0,001)$.

The order of 30 second push up measure of the students and athletes that who participated in our work is: the measure of sedanteries is $16, \pm 6,56$ times, the measure of wrestlers is $39,96 \pm 3,83$ times and the measure of handball players is $27,27 \pm 6,96$ times. According to discripancy between the groups, , there isn't explicit statistical discrepancy between the hanball players and wrestlers( $\mathrm{p}>0,005)$ but there is a consiredable statistical discripancy between the both wrestlers and hanball players and sedantaries $(\mathrm{p}<0,001)$.

The order of flexibility measure of the students and athletes that who participated in our work is : the measure of sedanteries is $17,77 \pm 6,78$ centimeters, the measure of the wrestlers is $26,28 \pm 5,84$ centimeters and the measure of the handball players is $25,92 \pm 4,58$ centimeters. . According to discripancy between the groups, , there isn't explicit statistical discrepancy between 
Alıcı O., \& İri R. (2015). 13- 15 yaș arasindaki güreșçiler hentbolcular ve sedanterlerin bazi fiziksel ve fizyolojik parametrelerinin karşilaştirilmasi. International Journal of Human Sciences, 12(1), 1070-1081. doi: $10.14687 /$ ijhs.v12i1.3117

the hanball players and wrestlers $(\mathrm{p}>0,005)$ but there is a consiredable statistical discripancy between the both wrestlers and hanball players and sedantaries $(\mathrm{p}<0,001)$.

Jump distance anaerobic strong of the athletes and students who participated in our work are measured.the order of jump distance is: the measure of sedanteries is $43,28 \pm 2,98$ centimeters, the measure of the wrestlers is $43,08 \pm 3,90$ centimeters, the measure of the handball players is $36,00 \pm 4,98$ centimeters.

According to discripancy between the groups, , there isn't explicit statistical discrepancy between the hanball players and wrestlers $(\mathrm{p}>0,005)$ but there is a consiredable statistical discripancy between the both wrestlers and hanball players and sedantaries $(p<0,001)$.

The result of Jump ofworking group was measured by using Lewis Formula and Anaerobic capacity of the groups was measured According to this result, the order of anaerobic power measure is: the measure of sedanteries is $63,06 \pm 1616,02 \mathrm{kgm} / \mathrm{s}$, the measure of the wrestlers is $78,55 \pm 17,17,46 \mathrm{kgm} / \mathrm{s}$ and the measure of the handball players is $78,67 \pm 1818,27 \mathrm{kgm} / \mathrm{s}$. According to discripancy between the groups, , there isn't explicit statistical discrepancy between the hanball players and wrestlers $(\mathrm{p}>0,005)$ but there is a consiredable statistical discripancy between the both wrestlers and hanball players and sedantaries $(\mathrm{p}<0,001)$.

FEV, FVC, VC and PEF of respiration parameters are measured in the group of students and athletics that participated in our work. The order of FEV1 measure of working group is : the measure of sedanteries is $2,64 \pm 0,67$ ( lt/secs), the measure of the wrestlers is $2,93 \pm 0,66(\mathrm{lt} / \mathrm{secs})$, the measure of the handball players is $2,86 \pm 0,58$ (lt/secs). According to discripancy between the groups, , there isn't explicit statistical discrepancy among all group $(\mathrm{p}>0,005)$.

The order of PEF measure of working group is: the measure of sedanteries is $317,73 \pm 66,97(\mathrm{lt})$, , the measure of the wrestlers is $320,60 \pm 77,07$ (1t), the measure of the handball players is $312,88 \pm 64,19$ (lt). According to discripancy between the groups, , there isn't explicit statistical discrepancy among all group $(\mathrm{p}>0,005)$.

The order of VC measure of working group is: the measure of sedanteries is $2,84 \pm 0,74(\mathrm{lt})$, the measure of the wrestlers is $3,44 \pm 0,83(\mathrm{lt})$, ), the measure of the handball players is $3,38 \pm 0,73(\mathrm{lt})$. According to discripancy between the groups, , there isn't explicit statistical discrepancy between the hanball players and wrestlers $(\mathrm{p}>0,005)$ but there is a consiredable statistical discripancy between the both wrestlers and hanball players and sedantaries $(\mathrm{p}<0,05)$.

Finally, when FVC measre is analysed, The order of F VC measure is: the measure of sedanteries is $2,81 \pm 0,74(\mathrm{lt})$, the measure of the wrestlers is $3,32 \pm 0,72(\mathrm{lt})$ and the measure of the handball players is $3,24 \pm 0,62$ (lt). According to discripancy between the groups, , there isn't explicit statistical discrepancy between the hanball players and wrestlers $(\mathrm{p}>0,005)$ but there is a consiredable statistical discripancy between the both wrestlers and hanball players and sedantaries $(\mathrm{p}<0,05)$.

As a result; it was found out that those who did sports in adolescent period had higher physical and physiological parameters than sedentaries. Again; in light of the study results; it was recommended that individuals should be encouraged to do sports regardless of sportive branches and their physical and physiological characteristics should be improved. 